\title{
O DESENVOLVIMENTO TERRITORIAL RURAL EM QUESTÃO
}

\author{
the rural territorial development in question
}

\author{
Hingryd Inácio Freitas* \\ Guiomar Inez Germani**
}

\begin{abstract}
Resumo
Este artigo traz algumas reflexões que vem sendo desenvolvidas no âmbito do Projeto GeografAR - A Geografia dos Assentamentos na Área Rural (POSGEO/UFBA/CNPq) - tendo como centralidade analítica a questão (da reforma) agrária no contexto da política de desenvolvimento territorial rural que, desde 2003 , vem sendo implantada pelo Estado de forma alicerçada ao discurso governamental de negação à concepção tecnocrático-economicista do desenvolvimento. Nesta perspectiva, entende-se que a reforma agrária é um processo estruturante do desenvolvimento uma vez que possibilita a democratização da base territorial de reprodução (i) material da vida e com isso, cria as condições favoráveis à autonomia política da prática social. Uma autonomia política que atribua concretude à cidadania e instrumentalize o desenvolvimento territorial rural em questão tendo como princípio político a territorialidade autônoma dos sujeitos sociais, em suas distintas temporalidades e espacialidades, com vistas à realização da justiça social no campo brasileiro.
\end{abstract}

Palavras-Chave: Política Territorial, Reforma Agrária, Desenvolvimento Rural.

\begin{abstract}
This article offers some thoughts that have been developed in the area of the GeografAR - The Geography of the Rural Settlements (POSGEO/UFBA/CNPq) - having as analytical centrality the issue of the agrarian (reform) within the context of the politic for the rural territorial development. Since 2003, this politic has been implemented by the State in a very solid way connected to the governmental speech of denying to the technocratic/economicist conception of development. In that perspective, it is understood that the agrarian reform is a structuring process of the development, once it makes possible to democratize the territorial base of (i) material reproduction of life and with that, it creates the favorable conditions to the political autonomy of the social practice. A political autonomy that gives solidity to the citizenship and instrument the rura territorial development focused in this study, and having as a political principle the autonomous territoriality of the social citizens in their different temporalities and spatialities, and yet, aiming to the concretization of social justice in the Brazilian countryside.
\end{abstract}

Key words: Territorial Politic, Agrarian Reform, Rural Development.

\begin{abstract}
Resumen
Este artículo propone algunas reflexiones que se han desarrollado en el marco del grupo de investigación GeografAR - La geografía de los asentamientos en las zonas rurales (POSGEO / UFBA / CNPq). Este artículo tiene como objeto central de análisis la reforma agraria en el contexto de la política de desarrollo rural territorial que, desde 2003, ha sido implementada por el Estado y que se caracteriza por un discurso gubernamental que nega la concepción tecnocrática y economicista del desarrollo. En esta perspectiva, se entiende que la reforma agraria es un proceso de estructuración del desarrollo pues permite la democratización de la base territorial y material de la vida, promocionando así condiciones favorables para la autonomía política de la práctica social. Esta autonomía política fortalece la ciudadanía e instrumentaliza el desarrollo rural teniendo como principio político la territorialidad de los sujetos sociales. Autónomos, en sus diferentes temporalidades y espacialidades, estes sujetos constituirán un logro para la justicia social en el campo brasileño.
\end{abstract}

Palabras clave: Política Territorial, Reforma Agraria, Desarrollo Rural.

(*) Prof ${ }^{a}$. Msc. da Licenciatura em Geografia do Instituto Federal da Bahia - Av. Araújo Pinho, n³9, CEP: 40110-150, Salvador (BA), Brasil. Tel: (+55 71)91728516-hifreitas@ifba.edu.br

(**) Bolsista Produtividade do CNPq e Profa. Dra. do Programa de Pós-Graduação em Geografia da Universidade Federal da Bahia - Rua Barão de Geremoabo s/n - Campus Universitário de Ondina-CEP: 40.170.115, Salvador (BA), Brasil, Tel: (+55 71) 33356249-guiomar@ufba.br 


\section{INTRODUÇÃO}

O modelo de desenvolvimento capitalista tornou-se hegemônico no campo brasileiro, tendo como alicerce histórico o padrão concentrador da estrutura fundiária. A concentração da propriedade da terra define relações desiguais de poder e de afirmação de direitos sociais no território que evidenciam contradições entre os discursos e as práticas da democracia com vistas à garantia da cidadania para o homem do campo. Dessa forma, entende-se que a realização da reforma agrária popular é uma condição estruturante para a democratização da vida social no campo brasileiro, em suas distintas temporalidades e espacialidades.

Nesta perspectiva, pretende-se analisar a Política de Desenvolvimento Territorial Rural, que, desde 2003, vem sendo implantada pelo Estado no campo brasileiro, pautada institucionalmente na gestão social das políticas públicas e no combate à pobreza rural. Ressalta-se que esta reflexão vem sendo desenvolvida no âmbito do Projeto GeografAR - A Geografia dos Assentamentos na Área Rural (POSGEO/UFBA/CNPq) - em especial, na linha de pesquisa “O Estado e a Questão Agrária", que tem como proposta analisar a permanência histórica da questão agrária no processo de ordenamento territorial rural promovido pelo Estado através do planejamento e gestão de suas políticas públicas.

\section{A GESTÃO SOCIAL DAS POLÍTICAS PÚBLICAS}

A implantação do Programa de Desenvolvimento Sustentável dos Territórios Rurais (PDSTR), a partir de 2003, no âmbito do Ministério de Desenvolvimento Agrário (MDA), representou a incorporação da abordagem territorial à política de desenvolvimento rural. Esta foi alicerçada no discurso governamental de negação à concepção tecnocrático-economicista do desenvolvimento que historicamente norteou as intervenções territoriais do Estado no campo brasileiro. Neste contexto, o território - um conceito interdisciplinar - foi instrumentalizado enquanto unidade de planejamento e de gestão espacial, sendo considerado a institucionalidade favorável à gestão social das políticas públicas.

Ressalta-se que a gestão social das políticas públicas foi instituída no Brasil a partir do pacto federativo da Constituição de 1988, no recente processo de redemocratização brasileira. Contudo, o centralismo autoritário retardou a implantação da descentralização política na gestão do espaço brasileiro, tendo sido este processo iniciado somente com o governo de Fernando Henrique Cardoso, em 1994, no vácuo da "flexibilização" na acumulação capitalista, com a Lei de Responsabilidade Fiscal. Assim, foram criados mecanismos de descentralização político-administrativa que redefiniram a relação do Estado - Sociedade e impulsionaram o avanço das lutas populares pela conquista dos direitos sociais definidores da democracia - igualdade, liberdade e participação política -, em suas múltiplas escalas e dimensões espaciais, tendo como utopia a corrosão do autoritarismo presente nos mais diversos aspectos da vida social.

Esta nova racionalidade de ordenação e uso do território é analisada por Becker (2006) a partir do paradigma da sustentabilidade. A autora argumenta que, no contexto geopolítico atual de controle da natureza como capital de realização futura, a sustentabilidade reside na proposta de harmonia espacial e equidade temporal do discurso que pode ser identificado através de princípios básicos, dentre os quais se insere a descentralização enquanto uma nova forma de planejamento e governo:

A gestão do território está baseada na parceria entre todos os atores do desenvolvimento e, através da discussão direta, as normas e ações são estabelecidas e responsabilidades e competências são definidas. Na verdade, a gestão é uma prática que visa a superar a crise do planejamento centralizado associada à crise do Estado. Ela expressa um fato novo: a incorporação do princípio das relações de poder (BECKER, 2006). 
No entanto, este processo revela-se de forma complexa considerando que esta mesma forma democrática do Estado assegura o direito legal da propriedade privada dos meios de produção - neste caso, a terra -, sendo mantida a exploração da força de trabalho como condição para a reprodução do capital. Assim, define-se uma sociedade estruturada em relações desiguais de poder e de afirmação de direitos entre os sujeitos sociais. Esta complexidade, por sua vez, adquire maior dimensão no campo brasileiro, considerando a sua especificidade funcional na Divisão Internacional do Trabalho (DIT) - definida pelo superávit primário da agroexportação monocultora - a partir da qual se definiu um padrão concentrador da estrutura fundiária.

A concentração da propriedade da terra no Brasil é historicamente constatada pelos dados estatísticos dos censos agrícolas e agropecuários do Instituto Brasileiro e Geografia e Estatística (IBGE), quando se analisa a relação inversamente proporcional entre o número de estabelecimentos rurais e a área total ocupada. Os dados do Censo Agropecuário de 2006, por exemplo, demonstram que os estabelecimentos com dimensão igual ou superior a 1.000 ha equivalem a $0,91 \%$ do total de estabelecimentos e ocupam $44,42 \%$ da área total do campo brasileiro. No outro extremo, $47,87 \%$ dos estabelecimentos estão concentrados no grupo de área com menos de 10 ha e detém 2,37\% da área. Dessa forma, perpetua-se historicamente o modelo colonial da agricultura exportadora espacializado na forma do latifúndio. Assim, o direcionamento capitalista do uso da terra para a geração de valor, seja como reserva de valor ou como valor de troca, impulsiona a sua apropriação concentrada como um "bem oligárquico" em que pelo seu controle quase que exclusivo busca-se o aumento do fluxo de renda fundiária (PORTO - GONÇALVES, 2001, p.2).

Convém lembrar o que nos ensina Marx (2008) que a terra em si não possui valor, pois não é fruto do trabalho do homem, mas tem um preço dado pela renda capitalizada. Assim, a apropriação privada da terra possibilita a extração da renda territorial - a renda capitalista da terra - enquanto lucro extraordinário permanente, ou seja, um componente particular da mais-valia. Neste sentido, a propriedade oligárquica da terra se define como condição material de extração da renda territorial, pois somente sendo "livre" o trabalhador poderá vender a sua força de trabalho na realização do contrato social - ainda que, contraditoriamente, a subordinação de relações sociais de produção não capitalistas também se defina como possibilidade de extração da renda territorial, seja enquanto renda da terra em trabalho, renda da terra em produto ou renda da terra em dinheiro.

Evidencia-se, assim, uma correlação desigual de poder entre as classes sociais no território, que, se define, de um lado, pelos capitalistas e proprietários fundiários que através da propriedade do meio de produção extraem a renda da terra, e, de outro lado, pelos trabalhadores assalariados e camponeses, que, enquanto força política coletiva de resistência à exploração da força de trabalho e expropriação dos meios de produção, organizam-se historicamente em movimentos sociais do campo.

Por sua vez, esta desigualdade repercute nas intervenções políticas do Estado que tendem a serem convergentes à territorialização do capital, favorecendo a especulação e a extração da renda da terra, ainda que pela "grilagem legalizada" de terras públicas, como afirma Oliveira (2007), ao analisar o caso da Amazônia brasileira a partir das intervenções do Instituto Nacional de Colonização e Reforma Agrária (INCRA SR 30 - Superintendência de Santarém). Na Bahia, estudos recentes desenvolvidos pelo Projeto GeografAR (2005) estimam que cerca de $55 \%$ do campo baiano seja equivalente às terras devolutas, sendo que em alguns municípios a área cadastrada é maior do que a superfície territorial, especialmente nas regiões do agronegócio e de expansão das fronteiras agrícolas, a exemplo do Oeste Baiano com a monocultura agroexportadora da soja.

Esta dimensão da ruralidade brasileira nos permite analisar a democracia a partir da perspectiva teórica de Chauí (2006) ao considerá-la um "instrumento ideológico", uma vez que os direitos não são concretamente assegurados para todos os sujeitos sociais sendo assim mantida a exploração econômica e a dominação política: 
A ideologia é um ideário histórico, social e político que oculta a realidade, e que esse ocultamento é uma forma de assegurar e manter a exploração econômica, a desigualdade social e a dominação política (CHAUí, 2006, p. 7).

As “instituições democráticas” reproduzem o conservadorismo político, sendo o poder - entendido através de Focault (1999) enquanto relação social que só existe em ação - exercido de forma autoritária pela manutenção do sistema vigente de dominação-subordinação. Assim, estabelece-se a contradição entre o discurso institucional da participação política e a prática do autoritarismo conservador a partir da qual se perpetua a apropriação do patrimônio público pelas elites políticas locais.

Neste contexto, a produção do discurso democrático revela-se como uma estratégia de abstração da materialidade social a fim de se garantir a manutenção de privilégios que violam os direitos sociais da democracia, como também considera Foucault (2006):

Suponho que em toda sociedade a produção do discurso é ao mesmo tempo controlada, selecionada, organizada e redistribuída por certo número de procedimentos que têm por função conjurar seus poderes e perigos, dominar seu acontecimento aleatório, esquivar sua pesada e terrível materialidade (FOUCAULT, 2006, p. 10). (grifo nosso)

O discurso se mostra também como uma estratégia de reprodução do poder que reprime o acontecer solidário da transformação social, como continua analisando o autor:

O discurso não é simplesmente aquilo que traduz as lutas ou os sistemas de dominação, mas aquilo por que, pelo que se luta, o poder do qual nos queremos apoderar (FOUCAULT, 2006, p.10).

Assim, ao operacionalizar a abordagem territorial instrumentalizando o território como unidade de planejamento e gestão do espaço, o Estado reproduz o discurso do consenso alicerçado no sentimento de pertencimento territorial, sendo este desconsiderado enquanto uma institucionalidade que evidencia as relações desiguais de poder e concretiza o conflito social. Dessa forma, o território é institucionalmente compreendido como:

Um espaço físico, geograficamente definido, geralmente contínuo, compreendendo a cidade e o campo, caracterizado por critérios multidimensionais - tais como o ambiente, a economia, a sociedade, a cultura, a política e as instituições - e uma população com grupos sociais relativamente distintos, que se relacionam interna e externamente por meio de processos específicos, onde se pode distinguir um ou mais elementos que indicam identidade e coesão social, cultural e territorial (MDA, 2005).

Nesta perspectiva, a identidade territorial - definida como sentimento de pertença sócio-político-institucional à dimensão espacial (MDA, 2005) - revela-se como uma representação espacial criada para legitimar a construção da nova ruralidade no imaginário social a fim de serem estabelecidas as relações consensuais necessárias à eficácia operacional do planejamento e da gestão do território.

Com estes aspectos, não se pretende negar o avanço do estímulo ao diálogo compartilhado no local entre as distintas instâncias do poder público e entre estas e as organizações e movimentos sociais. Analisando o histórico do clientelismo político brasileiro no qual o poder de decisão se restringia aos interesses político-partidários das prefeituras locais, a criação de institucionalidades territoriais mostra-se como uma importante conquista social. Entretanto, faz-se necessário ressaltar que numa sociedade estruturada em relações desiguais de poder entre as classes sociais e em que o direito à participação é indireto pela escolha de representantes - a democracia representativa -, a existência formal de instâncias políticas gestadas por forças sociais - ainda que na escala local não legitima, necessariamente, a participação democrática no território.

Entende-se, assim, que a gestão social das políticas públicas define novas possibilidades e também novos desafios ao exercício da cidadania. A depender da forma de condução do processo 
político, os desafios podem significar ameaças às possibilidades, principalmente quando as instâncias políticas se traduzem em "espaços institucionalizados", aflorando a chance de cooptação dos sujeitos sociais pela relação proximal com o poder institucional. Dessa forma, faz-se necessário um olhar crítico sobre as propostas recentes de governança democrática a partir do local, no momento em que a participação se transformou em uma nova ortodoxia no campo do desenvolvimento (ROMANO, 2007, p.9), sendo esta geralmente reduzida à existência formal das institucionalidades participativas.

\section{A POLÍTICA DE DESENVOLVIMENTO TERRITORIAL RURAL}

Estas novas formas de se pensar o planejamento e governo, explicitadas através do discurso político do desenvolvimento territorial rural - e que se definem a partir da negação à concepção tecnocrático-economicista do desenvolvimento -, nos remetem à reflexão de Souza (2006), ao considerar a "territorialidade autônoma" como o princípio desenvolvimentista, para além do crescimento econômico e modernização tecnológica, afirmando que:

[...] a possibilidade de se deter um controle significativo sobre o seu espaço vivido é, para uma coletividade, decisivo [...] sem ele, porém, falta um requisito indispensável à transformação dos indivíduos em cidadãos e à mobilização por um genuíno desenvolvimento (SOUZA, 2006, p.111).

Nesta perspectiva, a conquista do território se mostra como uma condição basilar para a autonomia dos sujeitos sociais no processo do desenvolvimento - uma vez que o referencial territorial é definidor das relações de poder - sendo assim atribuído o real significado à cidadania. Ressalta-se que esta compreensão da cidadania enquanto concretude relacionada à conquista da base de reprodução social é também compartilhada por Santos (2007, p. 144), ao afirmar que "a sociedade civil não se define fora do território, sendo assim impossível imaginar uma cidadania concreta que prescinda do componente territorial".

Isto significa dizer que a essência do desenvolvimento - seja "urbano" ou "rural" - é territorial. As possibilidades cotidianas de apropriação/produção/organização do espaço geográfico são definidoras da autonomia dos sujeitos sociais no processo político a fim de que se configurem (ou não) enquanto cidadãos. Assim, entende-se que em qualquer proposta de desenvolvimento que explicite como "norte geográfico" a redução da pobreza deve-se perpassar, estruturalmente, pelo processo de conquista, reconhecimento e manutenção dos territórios dos grupos sociais, em suas distintas temporalidades e territorialidades.

Entende-se, assim, que a reforma agrária é um processo estruturante do desenvolvimento uma vez que possibilita a democratização da base territorial de reprodução material e imaterial da vida, criando, também, as condições favoráveis à autonomia política da prática social. Uma autonomia política que atribua concretude à cidadania e instrumentalize o desenvolvimento territorial rural em questão tendo como princípio político a territorialidade autônoma dos sujeitos sociais, com vistas à realização da justiça social no campo.

No entanto, esta perspectiva de desenvolvimento se evidencia enquanto questão desafiadora no momento histórico atual marcado pela hegemonia das relações capitalistas de produção no campo brasileiro. Isto porque o desenvolvimento capitalista se materializa a partir da concentração dos meios de produção e exploração da classe trabalhadora e, consequentemente, concentração da riqueza produzida, aspectos estes que configuram uma negação perversa dos direitos sociais à vida e ao trabalho.

Por sua vez, esta negação tende a ser agravada para o homem do campo brasileiro, como também analisa Santos (2007):

O homem do campo brasileiro, em sua grande maioria, está desarmado diante de uma economia cada vez mais modernizada, concentrada e desalmada, incapaz de se premunir contra as vacilações da 
natureza, de se armar para acompanhar os progressos técnicos e de se defender contra as oscilações dos preços externos e internos, e a ganância dos intermediadores. Esse homem do campo é menos titular de direitos que a maioria dos homens da cidade, já que os serviços públicos essenciais lhe são negados, sob a desculpa da carência de recursos para lhe fazer chegar saúde e educação, água e eletricidade, para não falar de tantos outros serviços essenciais (SANTOS, 2007, p. 41-42).

É neste contexto que se insere a política de desenvolvimento territorial rural, sendo "o homem do campo" metaforizado pelos assentados da reforma agrária e agricultores familiares. A instrumentalização do uso do território pelo Estado - enquanto território rural - foi justificada pela busca de um projeto social igualitário de combate à pobreza e redução das desigualdades regionais, com vistas à promoção da "sustentabilidade". As relações sociais de produção estabelecidas são definidoras das (im)possibilidades rumo à cidadania rural. Com isso, a conquista do meio de produção - a terra - articulada com políticas de fomento à produção - a fim de que o trabalhador seja inserido de forma autônoma nas cadeias produtivas locais - configura-se como a espinha dorsal deste processo.

Teoricamente, o Estado reconhece esta questão ao definir a reforma agrária e a agricultura familiar como políticas instrumentalizadoras do desenvolvimento rural, ou melhor, ao reproduzir através do discurso governamental que estas políticas estão de "mãos dadas" com os territórios rurais:

Os territórios rurais estão de mãos dadas com duas políticas sociais mais do que relevantes. A primeira é a reforma agrária [...] para o governo federal a reforma agrária não se faz apenas com a cessão da terra. É fundamental que os assentados tenham acesso direto aos mecanismos que assegurem crédito, assistência técnica, educação, seguro e políticas públicas de agregação de valor à produção, assim como comercialização. [...] A outra política é o fortalecimento da agricultura familiar. Isso porque o governo federal tem como uma das suas missões mostrar para as sociedades brasileira e mundial que uma agricultura familiar fortalecida, ao contrário do que muitos acreditam, é uma enorme fonte de riqueza para o País. (MDA, 2005)

Contudo, o que vem se concretizando é a consolidação do modelo capitalista de desenvolvimento rural, sendo definida uma divisão territorial do trabalho que articula o agronegócio e a agricultura familiar. A articulação entre estas "formas-conteúdo" - aqui entendidas a partir de Santos (2008), enquanto formas geográficas que contêm frações do social - representa a supremacia da política agrícola no desenvolvimento territorial rural, sendo o agronegócio reafirmado como mantenedor do superávit primário pela agroexportação monocultora e a agricultura familiar refuncionalizada como dinamizadora das cadeias produtivas locais pela produção de gêneros alimentícios e matérias-primas para a indústria. Dessa forma, impõe-se a ordem do discurso da equidade social sustentado na garantia da retomada do crescimento econômico pelo aumento das exportações e na redução da pobreza pela integração dos agricultores familiares ao mercado como pequenos empreendedores rurais.

Esta supremacia da política agrícola é fragmentada nas estruturas de poder do Estado, considerando a segregação espacial da agricultura patronal e familiar representada de forma institucional pelo Ministério da Agricultura, Pecuária e Abastecimento (MAPA) e pelo Ministério do Desenvolvimento Agrário (MDA), respectivamente - além da hierarquização orçamentária, na qual os recursos destinados para a agricultura familiar representam, em média, $15 \%$ a $20 \%$ daqueles destinados à agricultura patronal (ainda que estes tenham aumentado significativamente nos últimos anos agrícolas).

Embora esta segregação seja justificada pelo governo federal como uma estratégia para a agricultura familiar ter acesso direto às políticas públicas - significando também um ganho real de habilidades para lidar com o aparelho burocrático do Estado - compreende-se que a mesma evidencia o atendimento institucional aos interesses das classes sociais que têm hegemonia no poder. Dessa forma, reproduz-se o viés setorial do econômico no planejamento estatal, sendo o rural dicotomizado 
entre o "agrícola" e o "agrário", como se a política agrícola não repercutisse nas relações sociais de produção e na estrutura da propriedade da terra.

A atual política agrária não estabelece como meta prioritária a criação de novos assentamentos rurais pelo cumprimento legal da função social da propriedade da terra. Prioriza-se a recuperação e a consolidação dos assentamentos já existentes pela ação concessiva de créditos de fomento à produção e infraestrutura com vistas à integração dos assentados nas cadeias produtivas locais, processo este que também desencadeia tensões e conflitos entre estes sujeitos sociais. Neste contexto, o Programa Nacional de Fortalecimento da Agricultura Familiar (PRONAF) mostra-se como o principal instrumento de política pública nos territórios rurais, tendo como ações prioritárias o fomento ao crédito produtivo e à infraestrutura territorial.

O Pronaf Crédito é gestado pela Secretaria da Agricultura Familiar (SAF), porém não se constitui em uma ação territorializada. Os projetos são obtidos diretamente pelos agricultores através da Declaração de Aptidão ao Pronaf que é emitida pelo MDA, através de entidades e órgãos credenciados (a exemplo dos sindicatos rurais e do INCRA), sendo analisados os critérios de regularização do CPF e adimplência do agricultor. Já o Pronaf Infra-Estrutura (PROINF) teve, a partir de 2003, a sua execução assumida pela Secretaria de Desenvolvimento Territorial (SDT) e, em 2005, foi incorporado ao Plano Plurianual 2004-2007 como uma ação denominada "Apoio a Projetos de Infraestrutura e Serviços em Territórios Rurais".

Os recursos do PROINF são destinados pelo Orçamento Geral da União (a fundo perdido) e operacionalizados através de convênios com a Caixa Econômica Federal e Banco do Nordeste do Brasil, através da elaboração de projetos técnicos de investimento em infraestrutura (entidades governamentais: estaduais e municipais) e de custeio de serviços públicos (entidades não governamentais). Para acessar estes recursos as entidades devem estar adimplentes e os projetos devem ter o caráter de integração territorial ou intermunicipal com viabilidade econômica para agregação de valor nas economias locais, atendendo, prioritariamente, a demanda social do MDA (agricultores familiares, assentados da reforma agrária, quilombolas, indígenas, pescadores artesanais e extrativistas).

Os projetos elaborados são submetidos a uma ordem de prioridade nos Colegiados Territoriais e encaminhados para os Conselhos Estaduais e às Delegacias Federais onde são avaliados e encaminhados para a SDT. É a escolha dos projetos que sustenta o discurso da governança democrática, como afirmou Sérgio Costa, o Articulador da SDT na Bahia:

A grande mudança de paradigma da política territorial foi o de delegar à sociedade, através dos colegiados territoriais, a escolha dos projetos a serem implantados em cada região. Veja, durante o Pronaf quem tinha o poder de decisão eram as prefeituras e agora é o colegiado territorial [...] (PESQUISA DE CAMPO realizada em 12.12.2008).

Isto também pode ser percebido no discurso da gestão social da política pública, reproduzido pelo então Ministro do MDA, Guilherme Cassel:

As condições dos agricultores familiares e dos assentados da reforma agrária melhoraram muito nos territórios, mais do que nos outros locais. Por quê? Por causa da organização da comunidade, do fato deles próprios elegerem suas prioridades, encaminharem juntos as suas demandas, fazendo com que o governo federal pudesse alocar recursos de forma mais racional. Então, foram oferecidos mais equipamentos, mais crédito, mais assistência técnica [...] (CASSEL, 2007, p.28-29).

De fato, a gestão local da política de desenvolvimento territorial tem como principal instância de poder o Colegiado Territorial. Entretanto, é importante ressaltar que uma instância colegiada é o espaço onde se estabelecem relações desiguais de poder - explicitadas nas indicações das ações prioritárias - e com isso a sua existência não define, necessariamente, a participação social, como acontece quando se efetivam recursos que não evidenciam as demandas sociais locais. Além disso, 
ao considerar o caráter representativo da participação social, sendo a representação um permanente objeto de disputa e de afirmação de legitimidade (que nem sempre se faz estritamente na esfera propriamente política) e a territorialidade desigual das classes sociais, cria-se a necessidade de indagação da natureza da representação, ou seja, dos grupos que são mobilizados e também das condições de participação, ou seja, de quem e como participa (DELGADO; BONNAL; LEITE, 2007, p. 26).

Outro aspecto importante a ser destacado é que, se comparado ao orçamento do agronegócio, o montante dos recursos do PRONAF (tanto relacionado ao crédito produtivo quanto à infraestrutura e custeio) é ínfimo. É um aspecto que reafirma o atendimento institucional aos interesses das classes sociais que tem hegemonia no poder constituindo-se, assim, num desafio ao desenvolvimento territorial rural.

Por fim, é importante ressaltar que este modelo de desenvolvimento territorial rural é uma expressão do Paradigma do Capitalismo Agrário (ABROMOVAY, 2007; VEIGA, 2007; FAVARETO, 2007), a partir do qual se atribui ao Estado o papel estratégico de fomentar a tecnificação do território para garantir a fluidez espacial do capital no campo. Fernandes (2004) destaca a inserção ideológica do Paradigma do Capitalismo Agrário nas esferas acadêmica e governamental em contraposição ao Paradigma da Questão Agrária (KAUTSKY, 1986; MARTINS, 1981), uma vez que o conflito por terra e o desenvolvimento rural são negados enquanto processos inerentes à contradição estrutural do capitalismo.

Nesse sentido, o autor afirma que:

A potencialidade do paradigma do Capitalismo Agrário é extraordinária e admirável. Como desdobramentos, esse paradigma espacializou-se em diferentes frentes por diversas direções e fincou territórios políticos, colocando em cheque o paradigma da Questão Agrária (FERNANDES, 2004, p. 21-22).

No entanto, a sujeição e a resistência à lógica do capital evidenciam-se enquanto unidade contraditória do modo de produção capitalista que se materializa no território pelo conflito de classe. Dessa forma, a questão agrária adquire concretude, sendo compreendida por Martins (1981, p.175) enquanto contradição estrutural do capitalismo que produz simultaneamente a concentração da riqueza e a expansão da pobreza e miséria, uma vez que a acumulação do capital impõe como necessidade a exploração da força de trabalho e esta, por sua vez, tem como essência a concentração dos meios de produção (neste caso, a terra). Compreende-se, assim, a "geografia desigual e combinada dos conflitos e violência no campo" enquanto componentes instituintes do desenvolvimento capitalista (PORTO - GONÇALVES, 2007, p.144), o que justifica a concentração espacial dos conflitos e violência no campo nas localizações em que o capital se territorializa.

A questão central que se coloca é como ser possível superar a dicotomia entre a pobreza e a riqueza, ignorando-as como expressões dialéticas da contradição estrutural do capitalismo - entre o capital e o trabalho - a partir da qual se configura como afirma Porto-Gonçalves (2007), uma "geografia desigual e combinada dos conflitos e violência no campo"? Um modelo de desenvolvimento definido pela hegemonia das relações capitalistas de produção não será capaz de superar esta contradição, ao contrário, reafirma-a.

O agronegócio caminha em direção oposta à própria sustentabilidade idealizada pelo Estado. A expansão de monoculturas agroexportadoras revela-se como sendo economicamente instável - pela vulnerabilidade do mercado internacional - e socialmente excludente - pela concentração fundiária e exploração do trabalhador -, além de dilapidar a natureza pela mercantilização dos recursos naturais. Impõe-se uma lógica racional da desigualdade (política, econômica, social) que concretiza a (re) produção de espaços hierarquizados/fragmentados/segregados.

Numa perspectiva desenvolvimentista democrática, os sujeitos sociais não podem ser redu- 
zidos a um "gueto temático" a partir de uma realidade projetada como uma unicidade totalizadora (SCHERER-WARNEN, 1993). A forma espacial de conteúdo familiar do trabalho e posse da terra adquire concretude no espaço a partir de distintas temporalidades e espacialidades. Com isso, a agricultura familiar não pode ser reduzida - enquanto uma tipologia social - ao viés político do empreendedorismo rural, sendo este imposto como o modelo único de superação da condição de pobreza dos camponeses e trabalhadores rurais.

Esta afirmação decorre de três aspectos a serem descritos: o primeiro é que considerando a seletividade espacial do capital, são inexistentes as condições reais para que todos os "pequenos com terra" se integrem no processo produtivo enquanto empreendedores rurais; o segundo é que existem unidades familiares de produção que possuem organizações sociais particulares, historicamente construídas, e projetam um modelo de desenvolvimento para além do capital; e o terceiro é que existe uma demanda explícita de "pequenos sem terra" que se organizam em redes de resistências e solidariedades pela conquista do território e estes por sua vez não podem ser ignorados.

A partir destes aspectos se evidenciam alguns questionamentos: qual a proposta de desenvolvimento para os sujeitos que ficam à margem do processo produtivo? E aqueles que reivindicam o direito social a terra como base de reprodução material e imaterial da vida? É possível pensar um projeto democrático de desenvolvimento territorial rural desconsiderando estas questões? Diante do exposto, acredita-se que não.

\section{A GEOPOLÍTICA DA REFORMA AGRÁRIA}

Uma reflexão sobre uma política pública, como a política da reforma agrária, explicita a necessidade analítica de se considerar o Estado enquanto instituição normatizadora do território nacional, relacionando-a ao contexto de cada país no sistema-mundo. No caso brasileiro, a origem da "pessoa jurídica de direito público" (Código Civil Brasileiro, Art. 41- I) foi alicerçada em matizes aristocrata e patrimonialista - sendo a terra institucionalizada como patrimônio aristocrata - que se perpetuam, constituindo-se atualmente no gargalo político mais difícil de transpor para a realização da reforma agrária.

Refletindo sobre as "raízes brasileiras", Buarque de Holanda (1995, p.160) afirma que a democracia foi sempre um lamentável mal entendido no Brasil, considerando que a "aristocracia" rural importou-a e tratou de acomodá-la onde fosse possível - à garantia de privilégios para a sua reprodução de classe no poder - sendo criminalizada a luta popular pela legitimação do direito público ao campo para a reprodução social da vida.

Assim, a reforma agrária se coloca como uma "questão" para o Estado e à Sociedade porque a sua realização pressupõe a superação deste "mal entendido histórico", considerando que se pauta no direito democrático e não o privilégio classista. A luta política pela conquista do território apresenta um sentido de movimento dado à lógica contraditória inerente ao modo de produção capitalista, não se limitando apenas ao momento de enfrentamento entre classes ou entre estas e o Estado. É neste sentido que Fernandes (2006, p.2) define a conflitualidade territorial como sendo "o processo em que se evidenciam os conflitos a partir da territorialização-desteterritorialização-reterritorialização de diferentes relações sociais, sendo estabelecidas temporalidades e espacialidades distintas".

Estes aspectos evidenciam a dimensão geopolítica da reforma agrária, uma vez que a mudança na estrutura da propriedade da terra é uma intervenção política no processo de reprodução do capital, o que repercute diretamente nas relações de poder, historicamente instituídas no território, a partir da concentração da propriedade da terra.

Concordando com Germani (2001, p. 137) entende-se que "este processo é definido a partir da correlação de forças na sociedade capitalista, sendo os enfrentamentos definidores do perfil e do alcance das soluções explicitadas para esta questão". É por isso que, apesar de ser uma política pública - legitimada constitucionalmente -, a reforma agrária é implantada pelo Estado brasileiro 
a reboque da ação organizada dos movimentos sociais enquanto uma política social compensatória das contradições capitalistas, restringindo-se à criação de assentamentos rurais dirigidos para o alívio das tensões e conflitos sociais no campo.

Configura-se, assim, um reformismo agrário - no qual as formas de intervenções espaciais do Estado são recriadas, permanecendo o conteúdo definidor da ação política que se utiliza da prática democrática conservadora de negação e violação dos direitos sociais. Neste caso, a negação do direito a terra para a reprodução social da vida no campo como previsto na Constituição da República Federativa do Brasil, de 1988:

Art. 184: Compete a União desapropriar por interesse social, para fins de reforma agrária, o imóvel rural que não esteja cumprindo a sua função social, mediante prévia e justa indenização em títulos de dívida agrária, com cláusula de preservação do valor real, resgatáveis no prazo de até vinte anos, a partir do segundo ano de sua emissão, e cuja utilização será prevista em lei.

Este reformismo agrário evidencia que as relações desiguais de poder também estão alicerçadas na composição orgânica do Estado, como avalia Ianni (1984) ao analisar "As Origens Agrárias do Estado Brasileiro", identificando que a concentração fundiária está diretamente associada ao processo de constituição do Estado e repercute diretamente na estrutura social do território brasileiro.

Neste sentido, Stédile (2005) destaca o berço agrário da burguesia industrial nascente e do modelo industrial dependente adotado, afirmando que:

As elites políticas - a burguesia industrial, agora no poder - fazem uma aliança com a oligarquia rural, tomam seu poder, mas mantêm como classe social, por duas razões fundamentais: primeiro, porque a burguesia industrial brasileira tem origem na oligarquia rural, da acumulação das exportações do café e do açúcar, ao contrário dos processos históricos ocorridos na formação do capitalismo na Europa e nos Estados Unidos. A segunda razão: o modelo industrial, como era dependente, precisava importar máquinas, e até operários, da Europa e dos Estados Unidos. E a importação dessas máquinas só era possível pela continuidade das exportações agrícolas, que geravam divisas para seu pagamento, fechando o ciclo da lógica da necessidade do capitalismo dependente (STÉDILE, 2005, p.30).

A força política da União Democrática Ruralista (UDR) e da Confederação da Agricultura e Pecuária do Brasil (CNA) nas estruturas do poder público, em suas distintas escalas e dimensões, confirma esta realidade histórica que vem se agravando com a consolidação da sociedade e da economia do agronegócio no Brasil, na qual a estrutura montada para a acumulação do capital está diretamente ligada a terra. A expansão do agronegócio significa a territorialização do capital monopolista no campo brasileiro, processo no qual as classes capitalistas - tanto a industrial (representada, principalmente, pelas empresas multinacionais) como a financeira (representada, principalmente, pelos bancos estrangeiros) - passaram a ser também o proprietário da terra apropriando-se da renda fundiária, seja enquanto valor de troca ou reserva de valor.

Este processo de monopolização do capital no campo vem configurando "a estrangeirização da propriedade fundiária no Brasil" (SAUER; LEITE, 2010), o que contradiz o princípio da soberania nacional e agrava a negação da democratização da vida social no campo.

Neste sentido, Porto-Gonçalves (2009) afirma que:

No Brasil, a Wolksvagem é proprietária de terra, assim como o Bradesco, o Itaú, o Daniel Dantas etc. E o que acontece nesses casos é que a terra fica improdutiva serve apenas como moeda de troca para receber financiamento (reserva de valor). Não sabemos se a Sadia ou a Perdigão são grupos agrários. Por isso eles se colocam contra a alteração dos índices de produtividade como determina a Constituição brasileira. Declarações do próprio presidente da Sadia afirmam que $80 \%$ dos lucros da empresa vêm do mercado financeiro. No entanto, ela recebe financiamento do BNDES destinado à agricultura e com respaldo da sociedade como se estivesse captando recursos para produzir alimentos. Para eles o agro é só mais um negócio. (PORTO-GONÇALVES, 2009, p.4) 
Considerando os antecedentes históricos da luta popular pela terra, é dessa forma que se entende a projeção tardia da reforma agrária no Brasil como uma política de Estado, como também os (des) caminhos no planejamento e na gestão política agrária em que a criação das normas legais e o cumprimento das metas estabelecidas perpetuam o passivo social do "deixando sempre a desejar". E mesmo com a institucionalização de diretrizes democráticas na política do desenvolvimento territorial rural em questão, a tradição conservadora do reformismo agrário permanece.

Com o início do governo Lula, em 2003, ressurgiu a esperança popular de realização da reforma agrária. Isto porque, como afirma Stédile (2005, p. 15), a hegemonia do debate e das idéias em torno do que deveria ser uma reforma agrária foi compartilhada, na década anterior, pelo Partido dos Trabalhadores (PT) e pelo Movimento dos Trabalhadores Rurais Sem Terra (MST). Tanto que houve, neste referido ano, o crescimento de $86,3 \%$ do número de ocupações e de $209 \%$ de acampamentos (CPT, 2003).

Dessa forma, a política agrária foi redirecionada para a construção de uma "Vida Digna no Campo" a partir da promoção do desenvolvimento sustentável e solidário no campo brasileiro (MDA, 2003). A reforma agrária e a agricultura familiar foram reafirmadas como políticas estratégicas, sendo então aprovado o II Plano Nacional de Reforma Agrária (II PNRA - 2003/2006) com a meta de assentamento de 400.000 novas famílias em projetos de reforma agrária, constatando o crescimento de $65 \%$ da meta orçamentária do Programa Nacional de Fortalecimento da Agricultura Familiar (PRONAF) no ano agrícola de 2003/2004 (o que equivaleu a oferta de R $\$ 4,5$ bilhões aos agricultores familiares).

A partir da viabilidade agrícola e da acessibilidade ao mercado, foram inicialmente definidas "áreas reformadas" para a convergência dos recursos públicos federais e, principalmente, criação dos novos projetos de assentamentos de reforma agrária. Entretanto, esta intervenção subvertia a dinâmica social da luta pela terra - uma vez que forçaria a migração das famílias acampadas para as áreas, que, por sua vez, não seriam as áreas reivindicadas - e com isso, foi grande a resistência popular das organizações e movimentos sociais que a interpretaram como uma estratégia de desmobilização política das ocupações e acampamentos de famílias sem-terra que, no referido momento histórico, se espacializavam de forma intensa pelo território nacional acirrando o conflito de classe.

Foi então que o governo federal incorporou a abordagem territorial do desenvolvimento rural enquanto política pública. As unidades de planejamento e gestão espacial das "áreas reformadas" foram substituídas pelos "territórios rurais" que, no discurso oficial, foram reproduzidos como construções sociais a partir das horizontalidades existentes entre agricultores familiares e assentados de reforma agrária na escala local.

No entanto, ainda que a reforma agrária seja reproduzida no discurso governamental como sendo um instrumento essencial para a promoção do desenvolvimento rural, a criação de novos assentamentos rurais pela ação desapropriatória do Estado não se evidencia enquanto questão estruturante na perspectiva adotada de desenvolvimento. Este processo se evidencia no orçamento e no cumprimento das metas oficialmente estabelecidas, o que garante a continuidade dos (des) caminhos da política da reforma agrária no campo brasileiro, nas diversas escalas espaciais.

Como demonstra a Tabela 1, em 2008, os programas que compõem o orçamento da reforma agrária sofreram uma redução orçamentária de $5,1 \%$, o que correspondeu a uma perda de R\$ 265.136.464 no orçamento. Neste contexto, destacou-se o Programa Desenvolvimento Sustentável de Projetos de Assentamento com uma redução de 31,6\% dos recursos originalmente alocados, ou seja, R\$ 83.796.156. Sendo que destes, 95,7\% (correspondendo a $\mathrm{R} \$ 80.192 .92$ ) referiram-se à ação de implantação e recuperação de infraestrutura básica nos assentamentos. Enfatiza-se, também, a diminuição de $7,8 \%$ dos recursos destinados à assistência técnica e capacitação de agricultores familiares e de assentados (paradoxalmente ao aumento da concessão de crédito de fomento à produção), o que representou um corte de $\mathrm{R} \$ 30.906 .800$ milhões na pauta de luta dos movimentos sociais do campo. 
Tabela 1- Programas: Valores previstos no Projeto de Lei Orçamentária Anual (PLOA 2008) para a Função: ORGANIZAÇÃO AGRÁRIA (RS)

\begin{tabular}{l|r|r|c}
\hline \multicolumn{1}{c|}{ PROGRAMA } & \multicolumn{1}{c|}{ PLOA } & \multicolumn{1}{c}{ Autógrafo } & \multicolumn{1}{c}{ (Autógrafo - PLOA) } \\
\hline Assentamentos para trabalhadores rurais & 965.231 .000 & 956.449 .600 & \multicolumn{1}{c}{$-8.781 .400$} \\
\hline Desenvolvimento sustentável de projetos de assentamentos & 1.997 .421 .726 & 1.913 .625 .570 & \multicolumn{1}{c}{$-83.796 .156$} \\
\hline Gerenciamento da estrutura fundiária e destinação de terras públicas & 78.402 .600 & 80.211 .359 & 1.808 .759 \\
\hline Gestão da política de desenvolvimento agrário & 34.950 .000 & 30.910 .000 & \multicolumn{1}{c}{$-4.040 .000$} \\
\hline Agricultura familiar (Pronaf) & 264.991 .011 & 267.966 .809 & \multicolumn{1}{c}{2.975 .798} \\
\hline Apoio administrativo & 496.381 .383 & 473.366 .126 & -23.015 .257 \\
\hline Crédito fundiário & 580.440 .817 & 517.100 .824 & -63.339 .993 \\
\hline Paz no Campo & 12.300 .000 & 10.300 .000 & -2.000 .000 \\
\hline Desenvolvimento sustentável dos territórios rurais & 245.436 .000 & 229.634 .630 & -15.801 .370 \\
\hline Brasil Quilombola & 77.800 .234 & 62.320 .188 & -15.480 .046 \\
\hline Educação no campo (Pronera) & 67.576 .471 & 55.016 .472 & -12.559 .999 \\
\hline Conservação, manejo e uso sustentável da agrobiodiversidade & 1.250 .000 & 1.250 .000 & 0 \\
\hline Assistência técnica e extensão rural na agricultura familiar & 395.990 .350 & 365.083 .550 & -30.906 .800 \\
\hline Cidadania e efetivação de direitos das mulheres & 29.500 .000 & 19.300 .000 & -10.200 .000 \\
\hline TOTAL & 5.247 .671 .592 & 4.982 .535 .128 & -265.136 .464 \\
\hline
\end{tabular}

Fonte: SIGA BRASIL/Senado Federal, 2008.

Elaboração: Projeto GeografAR, 2009.

Neste mesmo ano de 2008, o INCRA - enquanto órgão executor da reforma agrária - sofreu uma redução orçamentária de 7,9\%, o que correspondeu a uma perda de $\mathrm{R} \$ 191.867 .007$ no orçamento anual, como se observa na Tabela 2:

Tabela 2 - Unidades Orçamentárias: Valores previstos no Projeto de Lei Orçamentária Anual (PLOA 2008) para a Função: ORGANIZAÇÃO AGRÁRIA (RS)

\begin{tabular}{l|c|c|c}
\hline \multicolumn{1}{|c|}{ UNIDADE ORÇAMENTÁRIA } & PLOA & Autografo & (Autógrafo - PLOA) \\
\hline Ministério do Desenvolvimento Agrário (MDA) & 942.355 .610 & 930.992 .146 & -11.363 .464 \\
\hline Instituto Nacional de Colonização e Reforma Agrária (INCRA) & 2.423 .117 .982 & 2.231 .250 .975 & -191.867 .007 \\
\hline Recursos sob Supervisão do INCRA/MDA & 1.434 .938 .000 & 1.434 .938 .000 & 0 \\
\hline $\begin{array}{l}\text { Recursos sob Supervisão do Fundo de Terras e da Reforma Agrária/Banco da } \\
\text { Terra - MDA }\end{array}$ & 447.260 .000 & 385.354 .007 & -61.905 .993 \\
\hline TOTAL & 5.247 .671 .592 & 4.982 .535 .128 & -265.136 .464 \\
\hline
\end{tabular}

Fonte: Siga Brasil/Senado Federal, 2008.

Elaboração: Projeto GeografAR, 2009.

Em 2009, houve o agravamento deste contexto, tendo sido cortados "em função da crise financeira mundial" $41 \%$ dos recursos aprovados para a desapropriação e a assistência técnica das famílias assentadas. Isto significa dizer que os R $\$ 957$ milhões aprovados para as ações desapropriatórias foram reduzidos para $\mathrm{R} \$ 561$ milhões e que os R $\$ 224$ milhões aprovados para a assistência técnica das famílias assentadas foram reduzidos para R $\$ 135$ milhões, o que também contradiz o discurso governamental de consolidação dos assentamentos rurais existentes (CPT, 2009).

O mesmo ocorreu em relação ao (des) cumprimento das metas estabelecidas no II PNRA, como analisa Oliveira (2007), constatando que, em média, apenas um terço das metas das novas famílias assentadas foi atingido, o que configurou a "NÃO Reforma Agrária do MDA/INCRA no governo LULA”. Segundo os dados elaborados pelo Laboratório de Geografia Agrária USP/Instituto Iandé, 
o governou cumpriu apenas 32,9\% da Meta 1 (assentamento de 400.000 novas famílias), sendo assentadas 131.745 novas famílias a partir da política de reforma agrária. Contudo, as estatísticas governamentais agregaram todas as famílias beneficiadas com as RBs - Relação dos Beneficiários - pela execução das distintas políticas agrárias (reforma agrária, regularização fundiária, reordenamento fundiário e reassentamento fundiário). Outro aspecto importante foi a reprodução da espacialização da política de reforma agrária do Estado que concentrou as suas intervenções fundiárias no Nordeste (52\%) e Norte (24\%), assim como ocorrera no I PNRA.

$\mathrm{Na}$ Bahia, foi definida a meta de assentamento de 27.200 famílias para o período 2004-2007 (II PNRA, 2004), entretanto, de acordo com os dados elaborados pelo Projeto GeografAR, foram assentadas apenas 7.365 famílias, o que corresponde a 27,07\% da meta estabelecida (de forma análoga à média nacional). Neste período, foram implantados 138 projetos de reforma agrária que abrangem uma área reformada de 272.637,96 ha.

Assim, a questão (da reforma) agrária foi redefinida no contexto da política de desenvolvimento territorial rural enquanto processo de transformação dos assentamentos rurais em espaços de produção com viabilidade econômica e, com isso, a necessidade estrutural do acesso a terra vem sendo escamoteada pelo marketing político do fortalecimento da agricultura familiar que adquire concretude nos territórios rurais através do financiamento dos projetos territoriais de custeio à produção e à infraestrutura.

Com isso, não se pretende ignorar a importância de serem criados mecanismos governamentais que viabilizem a produção agrícola nos assentamentos rurais. Ao contrário, esta é uma condição basilar para a conquista da autonomia produtiva dos assentamentos rurais e reprodução social das "campesinidades" espacializadas em cada lugar. Segundo o IPEA (2011), os camponeses são o grupo social mais atingido pela pobreza extrema do Brasil. Entre as famílias consideradas "extremamente pobres", 36\% tinham como fonte de renda, em 2009, a produção agrícola. Os principais fatores que levam os camponeses à pobreza são, pela ordem, o pequeno tamanho de suas terras; a baixa disponibilidade de insumos agrícolas, especialmente de água; a falta de assistência técnica; e os baixos preços pagos pelos seus produtos. Outro destaque foi relaciona-se à concentração espacial de mais de $30 \%$ dos extremamente pobres na zona rural de pequenos municípios do Nordeste.

No entanto, reafirma-se a compreensão de que uma ação política do Estado - enquanto instituição normatizadora do território nacional - com vistas à desconcentração da riqueza e do poder deve perpassar estruturalmente pela democratização dos meios de produção (e neste caso, a terra). A partir do momento no qual o viés economicista é instituído enquanto essência do processo político, a geopolítica da reforma agrária passa a ser mascarada pela identidade de pertencimento territorial que busca tornar igual o que é essencialmente desigual. Afinal de contas, a mudança na estrutura da propriedade na terra repercute na estrutura produtiva e, assim, nas relações sociais de poder historicamente definidas entre as classes sociais no campo.

A concentração de poder define uma sociedade não democrática. E, no caso brasileiro, em que as relações de poder estão estruturadas na propriedade concentrada da terra, a "reforma agrária é democracia" como afirma Porto-Gonçalves (2009):

Mas digo que um dos piores efeitos de não se fazer Reforma Agrária ainda é a questão da democracia. A Reforma Agrária insisto, não é uma questão econômica, mas sim democrática, o que significa dizer que a sociedade brasileira jamais será democrática enquanto tivermos os latifúndios empresariais e os monocultivos expulsando o povo. Concentração de poder é contrário de democracia. É oligarquia. (PORTO-GONÇALVES, 2009, p.6-7)

A não realização da política de reforma agrária significa a permanência do lamentável "mal entendido" histórico da democracia no Brasil, como afirma Buarque de Holanda (1995). E na continuidade desta permanência, a questão (da reforma) agrária continuará geografizando-se, no tempo-espaço, e se colocado enquanto "questão de democracia" para o Estado brasileiro. Neste 
processo, trabalhadores rurais e camponeses, organizados enquanto força política coletiva de resistência à exploração da força de trabalho e expropriação dos meios de produção, se espacializam a partir de conflitos territoriais que tornam evidentes as contradições estruturais do desenvolvimento capitalista no campo brasileiro.

\section{CONSIDERAÇÕES FINAIS}

Com esta reflexão, se buscou analisar a questão (da reforma) agrária enquanto concretude das contradições estruturais do modelo de desenvolvimento capitalista que se tornou hegemônico no campo brasileiro. Esta questão, por sua vez, institucionalizada pelo Estado enquanto política pública torna-se uma condição estruturante para o desenvolvimento territorial rural alicerçado na democratização da reprodução social da vida no campo.

Contudo, a essência geopolítica da reforma agrária define as (im) possibilidades à cidadania do homem do campo no que se refere, especialmente, à conquista da territorialidade autônoma. Mesmo no contexto político de negação à concepção tecnocrática e economicista do desenvolvimento definido no discurso governamental, o reformismo agrário faz permanecer o lamentável "mal entendido" histórico da democracia no Brasil a partir do qual se reproduz o padrão de concentração da propriedade da terra e com isso, da riqueza e do poder.

Evidencia-se, assim, que a implantação da política de desenvolvimento territorial rural instrumentaliza a (des) ordem no território ao buscar camuflar a permanência histórica da questão agrária brasileira, ainda que esta seja, cotidianamente, reafirmada como um desafio tanto para o Estado como para a Sociedade com diretas repercussões socioespaciais no campo e na cidade.

\section{REFERÊNCIA BIBLIOGRÁFICA}

ABRAMOVAY, Ricardo. Paradigmas do Capitalismo Agrário em Questão. $3^{\text {a }}$ edição. São Paulo: EDUSP, 2007.

BECKER, Bertha Koiffmann. A Geopolítica na Virada do Milênio: logística e desenvolvimento sustentável. In: CASTRO, Iná Elias de; GOMES, Paulo Cesar da Costa; CORRÊA, Roberto Lobato. Geografia: Conceitos e Temas. $8^{a}$ edição. Rio de Janeiro: Bertrand Brasil, 2006. p. 271-307.

BUARQUE DE HOLANDA, Sérgio. Raízes do Brasil. 26a edição. São Paulo: Companhia das Letras, 1995. CASSEL, Guilherme. Territórios Rurais vão ser ampliados. Territórios Rurais. Brasília. Ano 3 . n. 2, p. 28-29, jul./dez.2007

CHAUÍ, Marilena. O Que é Ideologia. São Paulo: Brasiliense, 2006.

CPT. Comissão Pastoral da Terra. Conflitos no Campo - Brasil 2003. Goiânia: CPT, 2003.

CPT. Comissão Pastoral da Terra. Balanço da Política Agrária do Governo Federal em 2009. Disponível em http: <//www.mst.org.br>. Acesso em 01.03.2010.

DELGADO, Nelson Giordano; BONNAL, Philippe; LEITE, Sérgio Pereira. Desenvolvimento Territorial: Articulação de Políticas Públicas e Atores Sociais. Relatório Final. Rio de Janeiro: OPPA/CPDA/UFRRJ - IICA, 2007.

FAVARETO, Arilson. Paradigmas do Desenvolvimento Rural em Questão. São Paulo: FAPESP, 2007.

FERNANDES, Bernardo Mançano. Questão Agrária: Conflitualidade e Desenvolvimento Territorial, 2004. Disponível em: <http://www4.fct.unesp.br/nera/artigodomes/Desenvolvimento_territorial.pdf $>$ Acesso em 05.05.2006.

FOUCAULT, Michel. Microfísica do Poder. Rio de Janeiro: Graal, 1999.

FOUCAULT, Michel. A Ordem do Discurso. São Paulo: Loyola, 2006.

GEOGRAFAR - A Geografia dos Assentamentos na Área Rural. Leitura geográfica da Estrutura

Fundiária da Bahia. Banco de Dados. Salvador, 2005. Disponível em: <http://www.geografar.ufba.br $>$. Acesso em 05.05.2009. 
GERMANI, Guiomar Inez. Reforma Agrária: ações públicas e movimentos sociais. Caderno de Geociências. Salvador: EDUFBA, 2001.p. $133-144$.

IANNI, Octávio. Origens Agrárias do Estado Brasileiro. São Paulo: Brasiliense, 1984.

IBGE. Instituto Brasileiro de Geografia e Estatística. Censo Agropecuário, 2006. Rio de Janeiro: IBGE, 2006. IPEA. Instituto de Pesquisas Econômicas Aplicadas. Camponeses são os mais afetados por pobreza extrema no Brasil. Disponível em < http: // noticias. http://noticias.uol.com.br/cotidiano/2011/09/15/camponeses-sao-os-mais-afetados-por-pobreza-extrema-no-brasil-aponta-ipea.jhtm. Acesso em: 17.09.11

KAUTSKY, Karl. A Questão Agrária. Rio de Janeiro: Lammert, 1986.

MARTINS, José de Souza. Os Camponeses e a Política no Brasil. Petrópolis: Vozes, 1981.

MARX, Karl. O Capital. Livro 3: O Processo Global de Produção Capitalista. Volume VI. Rio de Janeiro: Civilização Brasileira, 2008.

MDA. Ministério do Desenvolvimento Agrário/Instituto Nacional de Colonização e Reforma Agrária. Vida Digna no Campo. Brasília: MDA/SDT, 2003.

MDA. Ministério do Desenvolvimento Agrário/Secretaria de Desenvolvimento Territorial. Marco Referencial para Apoio ao Desenvolvimento de Territórios Rurais. Brasília: MDA/SDT, 2005.

OLIVEIRA, Ariovaldo Umbelino. Modo de Produção Capitalista, Agricultura e Reforma Agrária. São Paulo: Labur Edições, 2007.

PORTO-GONÇALVES, Carlos Walter. Meio Ambiente, Ciência e Poder: diálogos de diferentes matrizes de racionalidade. In: SPOSATI, Adailza et al. Ambientalismo e Participação na Contemporaneidade. São Paulo: EDUC/FAPESP, 2001. p.135-161.

PORTO-GONÇALVES, Carlos Walter. A Oligarquia Fazendo Justiça com as Próprias Mãos (A geografia da violência no campo brasileiro 2007) Caderno Conflitos no Campo - Brasil 2007. Goiânia: Comissão Pastoral da Terra, 2007. p.143-148

PORTO-GONÇALVES, Carlos Walter. Reforma Agrária e Democracia, ou melhor, Reforma agrária é Democracia. Entrevista do Setor de Documentação da Comissão Pastoral da Terra em Olinda (PE), em 28/12/2009.

ROMANO, Jorge O (org.). Olhar Crítico Sobre Participação e Cidadania: a construção de uma governança democrática e participativa a partir do local. São Paulo: Expressão Popular, 2007. (Coleção Olhar Crítico, 1). SANTOS, Milton. O Espaço do Cidadão. $7^{\mathrm{a}}$ edição. São Paulo: EDUSP, 2007.

SANTOS, Milton. Espaço e Método. São Paulo: EDUSP, 2008.

SAUER, Sérgio; LEITE, Sérgio Pereira. A Estrangeirização da Propriedade Fundiária no Brasil. Observatório de Políticas Públicas para o Brasil. No 36 - Agosto 2010.

SHERER-WARREN, Ilse. Redes de Movimentos Sociais. São Paulo: Loyola, 1993.

SOUZA, Marcelo José Lopes O Território: sobre espaço de poder, autonomia e desenvolvimento. In: CASTRO, Iná Elias de; GOMES, Paulo Cesar da Costa; CORRÊA, Roberto Lobato. Geografia: Conceitos e Temas. $8^{a}$ edição. Rio de Janeiro: Bertrand Brasil, 2006. p. 77-116

STÉDILE, João Pedro (org.). A Questão Agrária no Brasil: O debate na esquerda 1960-1980. São Paulo: Expressão Popular, 2005.

VEIGA, José Eli da. O Desenvolvimento Agrícola: Uma Visão Holística. São Paulo: EDUSP, 2007.

Trabalho enviado em maio de 2012

Trabalho aceito em junho de 2012 